\title{
CONFERENCIAS
}

\section{O CONCEITO DA ESCOLA NEUROLÓGICA DE MONTREAL SÔBRE A EPILEPSIA}

\author{
Patro Pinto Pupo*
}

$O$ advento dos métodos de amplificação eletrônica criou etapa inteiramente nova no estudo da neurofisiologia cerebral; com êles tornou-se possível a amplificação e o registro gráfico dos potenciais elétricos cerebrais espontâneos, assim como o dos potenciais induzidos pela excitação elétrica ou química de áreas da substância cinzenta cerebral.

Com o registro dos potenciais elétricos cerebrais espontâneos teve origem a eletrencefalografia, que passou, logo, do campo da neurofisiologia pura para o da clínica. A descoberta de que as crises epilépticas se acompanham de descargas elétricas neuronais de grande intensidade, e mais ainda, de que essas descargas se processam no cérebro dos pacientes de epilepsia mesmo nos intervalos livres de ataques, abriu novo e inienso campo de estudos no terreno das epilepsias; essas descargas foram registradas no eletrencefalograma e se tornaram universalmente conhecidas sob a denominação de "disritmias".

Com o registro dos potenciais elétricos cerebrais induzidos teve início a chamada "neuronografia", novo método que veio revolucionar inteiramente os nossos conhecimentos sôbre a anatomia fina e a fisiologia cerebrais. Teve particular desenvolvimento o método da estricninização de Dusser du Barenne (excitação de determinadas áreas cinzentas cerebrais com a deposição de estricnina e o registro dos potenciais elétricos de descarga neuronal em áreas distantes, sendo demonstradas, assim, correlações anatômicas di. retas entre umas e outras), com o qual foi possível o estudo de correlações anatômicas de tôdas as áreas corticais cerebrais, mesmo aquelas até então parcialmente conhecidas ou de todo desconhecidas, quer com outras áreas corticais, quer com núcleos cinzentos centrais. Com isso surgiu um mapa inteiramente novo de correlações anatômicas funcionais no cérebro.

Das estruturas cerebrais, o tálamo foi das que mais lucrou com os novos métodos de pesquisa. Nossos conhecimentos sôbre ćle, que vinham do século XIX e se restringiam aos seus núcleos correlacionados com as funções de sensibilidade (núcleos que recebem as vias aferentes provindas dos

Conferência proferida no Departamento de Neuro-Psiquiatria da Associação Paulista de Medicina em 7 fevereiro 1950.

* Livre-Docente de Clínica Neurológica na Fac. Med. da Univ. de São Paulo e Chefe de Clínica Neurológica na Esc. Paulista de Medicina (Prof. Paulino W. Longo). 
órgãos receptivos periféricos e em parte transmitem os seus imıulsos às áreas do córtex cerebral com função sensitiva elementar), tinham sido acrescidos de poucos mais, mostrando outras conexóes tálamo-corticais e mostrando a existência de núcleos talâmicos sem ligações diretas com o córtex cerebral. Nestas duas últimas décadas, entretanto, com o auxílio da neuronografia, foi feita completa revisão de tudo e o tálamo aparece, hoje, como o sistema de núcleos mais importantes do encéfalo, mantendo correlações diretas e com exata discriminação topográfica, pràticamente com tôdas as áreas corticais cerebrais.

Se a neuronografia, juntamente com os métodos histulógicos finos, possibilitou êsse notável avanço, a eletrencefalografia e a eletrocorticografia proporcionaram campo para um novo estudo - a influência dos diversos núcleos talâmicos sôbre o funcionamento cerebral. A excitação química ou elétrica, ou a destruição experimental dos núcleos talâmicos do grupo dorsal, isto é, os que têm correlação anatômica topográfica bem precisa com as diversas áreas cerebrais corticais, determina alterações imediatas, passageiras ou duradouras, no eletrocorticograma. Essas alterações consistem em surtos de ondas rápidas ou lentas sobrepostas aos ritmos de base com 8 a $12 \mathrm{c} / \mathrm{s}$, o qual permanece inalterado; tais surtos são restritos às áreas corticais correspondentes aos núcleos excitados. Entretanto, a partir de 1942 , os trabalhos de Morrison e Dempsey ${ }^{18}$ vieram demonstrar a existência de núcleos talâmicos outros, cuja excitação repercute em tôda corticalidade cerebral de modo síncrono, alterando a atividade elétrica rítmica do cérebro em repouso. Essas pesquisas levaram êstes autores a admitir a existência de um verdadeiro sistema funcional intratalâmico, capaz de sincronizar tôda a corticalidade cerebral de acôrdo com as excitaçôes elétricas experimen. tais e, mesmo, de determinar respostas secundárias segundo ritmos por êle induzidos. Correlatamente a isto estão as descrições de Rose e Woosley ${ }^{20}$ do sistema reticular talâmico, em seguimento anatômico e funcional aos sistemas reticulares do tronco cerebral, descritos por Magoun e col. ${ }^{13}$, os quais têm função de contróle dos sistemas inferiormente situados, particularmente os da motricidade e do tono muscular. Rose e Wooslcy admitiram estar nesses sistemas anatômicos a sede dos sistemas funcionais descritos por Dempsey e Morrison.

Dêste modo, o sistema reticular tálamo-hipotalâmico pode ser considerado como um verdadeiro regulador (pacemaker) que controla tôda a função rítmica do córtex cerebral. Daí partiram os estudos experimentais de Jasper e col., no Montreal Neurological Institute ${ }^{7,12,13}$, os quais, em gatos e macacos, excitando com o aparêlho estereotáxico de Horsley-Clark, estudaram a topografia dêsses núcleos intradiencefálicos e a influência que tais excitações exercem sôbre o eletrocorticograma. Seus resultados, em síntese, mostram a existência de vários núcleos medianos ou paramedianos cuja estimulação elétrica determina respostas globais no córtex, inibindo os ritmos de repouso, determinando o aparecimento de ritmos outros e mesmo de ritmos lentos e rápidos intercalados, idênticos aos encontráveis nos pacientes epilépticos. Há núcleos com respostas diferentes e o estudo de sua topografia ainda continua. As vias de projeção dêsses núcleos são difusas a 
tôda a corticalidade (seja para as áreas de projeção talâmica já bem conhecida, seja para as não perfeitamente conhecidas) poi vias tálamo-corticais multissinápticas.

No estado atual de nossos conhecimentos sôbre a fisiologia cerebral, a evidenciação da existência de tal sistema reticular tálamu-hipotalâmico, com ação tão preponderante sôbre a atividade elétrica cortical cerebral, vem dar notável unidade ao funcionamento dos diversos sistemas cerebrais. A ação já demonstrada do sistema reticular talâmico sôbre o ritmo elétrico cerebral de repouso, o conhecimento atual de que é o fenômeno de atenção (e não o estimulo visual ou sensitivo em si) que inibe êsse ritmo de repouso, a demonstração anterior de Magoun de que os sistemas reticulares do tronco cerebral mantêm o estado de ativação cortical (atenção), fazem cornpreender que a interação dêsses dois segmentos do sistema reticular permite manter o cérebro num estado de receptividade tal que todos os elementos que lhe são trazidos pelas vias aferentes sensoriais (vista, audição, olfato, etc.) e sensitivas (externas ou internas) possam ser integrados num todo e possam determinar reações de conjunto, uniformes, adaptando em tempo e em qualidade as reações individuais às condições de cada momento no ambiente. São os sistemas reticulares, tão difusamente intercorrelacionados, os verdadeiros coordenadores da ação cerebral como um todo uniforme.

\section{FISIOPATOLOGIA DA CRISE EPILEPTICA}

Os resultados dêsses novos conhecimentos sôbre o papel do sistema reticular diencefálico no funcionamento cerebral evoluíram paralelarnente ao progresso de novos conhecimentos sôbre a fisiopatologia da crise convulsiva.

A velha e sólida concepção jacksoniana da crise convulsiva epiléptica como súbita descarga neuronal, que vinha tendo paulatinamente o apôio dos dados obtidos por Penfield e colaboradores em dois decênios de labor cotidiano com epilépticos, quer excitando o córtex cerebral durante as intervenções cirúrgicas para extirpação de focos epileptógenos, quer em estudos anátomo-clínicos detalhados, teve, com a eletrencefalografia, uma comprovação integral e um desenvolvimento sem par.

A descarga neuronal é igual, qualquer que seja a asquitetura da substância cinzenta afetada; a diferença clínica da síndrome provocada depende das diferenças funcionais das áreas afetadas — sensitivo-motora, pré-frontal, occipital, temporal, rinencefálica ou diencefálica - e da propagação da descarga inicial. Dêste modo, a crise epiléptica bravais-jacksoniana (sômato-sensitiva, sensorial ou psíquica), o pequeno mal epiléptico, o ataque psicomotor e o grande mal epiléptico têm uma fisiopatologia idêntica quanto ao início ${ }^{10,}{ }^{11}$.

A descarga neuronal quando é cortical e, portanto, próxima do eletrodo do examinador, aparece sob a forma de uma oscilação rápida de potencial elevado ( 10 a 20 milissegundos de duração e 200 a 500 microvolts de oscilação), inicialmente negativa, e dá lugar a oscilações subseqüentes (after-discharge) progressivamente de menor potencial e mais lentas. Estas oscilações rápidas são chamadas espículas (spikes). Elas podem ser iso- 
ladas ou agrupadas, são focais e, quando intensas, se prippagain para áreas distantes ou, no mais das vêzes, para áreas homólogas do hemisfério oposto, por via das conexões anatômicas que ligam essas regiōes.

Quando a descarga se dá em áreas cinzentas ocultas (isto é, situadas nos sulcos intergirais ou em circunvoluções ocultas - circunvolução da face medial temporal ou frontal, ou circunvolução da ínsula, por exemplo), no eletrencefalograma são apanhadas, não mais as descargas originais, mas os efeitos de sua difusão às áreas vizinhas e, portanto, aparecem, não mais como espículas, mas como ondas ainda de início rápido, mas de muito maior duração e irregularidade (ondas "sharp"). Estas também definenı o foco epileptógeno.

Quando a descarga cortical-focal é suficientemente intensa, determina a eclosão de distúrbios rítmicos, bilaterais, síncronos, por ondas de $6 \mathrm{c} / \mathrm{s}, 5$ $\mathrm{c} / \mathrm{s}, 4 \mathrm{c} / \mathrm{s}$ e até $3 \mathrm{c} / \mathrm{s}$, e de elevado potencial; além disso, o "complexo ondas e espículas", de início preponderante nas áreas cerebrais anteriores, se difunde, depois, por tôda a corticalidade. Estes são devidos à participação dos sistemas profundos — sistema reticular tálamo-hipotalâmico - agora ativados pela descarga do foco epileptógeno que lhe foi transmitida pelas vias de conexão córtico-diencefálica. A descarga epileptógena, de simples que era - focal, evidenciando-se por uma sucessão de espículas e ondas lentas de difusão, aparecendo sôbre o funcionamento rítmico do cérebro em repouso (ritmo $\alpha$ ) - transmutou-se em uma sucessão de ritmos complexos e bem organizados, com freqüências lentas e ondas de elevado potencial, substituindo os ritmos cerebrais de repouso. Na primeira fase, tínhamos um foco ativo dando descargas locais e não afetando o funcionaniento das demais áreas cerebrais e, muito menos, do cérebro como um todo; na segunda, a descarga epiléptica não é mais um fenômeno local e sim uma descarga síncrona de um sistema regulador central que recruta em seu ritmo todo o funcionamento cerebral.

Paralelamente a êsses fenômenos elétricos da crise convulsiva epiléptica secundária a um foco cortical, evoluem as manifestações clínicus. Supondo-se, com finalidade meramente explicativa, que êsse foco esteja localizado em área cortical motora correspondente ao polegar direito, a crise se inicia com parestesias restritas a êste dedo, logo seguidas de movimentos clônicos também locais; progressivamente se dá a extensão dêsses fenômenos aos demais dedos, a mão, à hemiface, a todo membro superior e, muitas vêzes, ao membro inferior. E' o exemplo mais elementar da epilepsia bravaisjacksoniana. O paciente, consciente, observa tudo o que se passa consigo e o que se passa no ambiente exterior. Na fase seguinte, caso a crise seja suficientemente intensa, as manifestações parestésicas e motoras tendem a tomar os membros do lado oposto, o paciente perde a consciência, assim como perde o contrôle tônico postural e cai; a grande crise tônico-clônica tem, então, lugar (crise do grande mal epiléptico). Eletrencefálogràficamente, as manifestações focais correspondem à primeira fase, enquanto que a eclosão das disritmias bilaterais síncronas correspondem à segunda fase. Elas são indício de que um sistema central controlador do funcionaniento cerebral em sua totalidade foi pôsto em ação, ativado pela "faísca" do 
foco epileptógeno cortical. Este continua a existir, mas não tem mais qual. quer interferência no que se está passando; a descarga convulsiva cerebral, uma vez desencadeada, vai até o fim, até a exaustão dos elementos neuronais por ela tomados. Na fase final, significando essa exaustão, não há, no eletrencefalograma, nem as descargas síncronas e de elevado potencial da crise, nem as oscilaçóes ritmadas e de freqüência constante do funcionamento cerebràl de repouso, mas sim oscilações bastante lentas em tôdas as áreas cerebrais examinadas.

Isto é o que se passa na crise epiléptica por lesão focal cortical. Na epilepsia tipo pequeno mal (P.M.), pelo contrário, a eclosão das disritmias bilaterais difusas é o primeiro sinal eletrencefalográfico, tal como a perda da consciência é a primeira manifestação clínica. Neste caso, a descarga inicial se deu originàriamente em centros diencefálicos, envolvendo inicial. mente o sistema reticular tálamo-hipotalâmico. A crise do P.M. condiz com uma perda súbita e passageira de consciência e manutenção do contrôle dos sistemas de estática e dos automatismos motores.

A descarga neuronal eletrencefalogràficamente registrada é de curta duração: fração de segundo ou, no máximo, um a dois segundos. Quando essa descarga é mais intensa e duradoura, há lugar para manifestações outras, como perda do tono de postura e queda do paciente, contraçôes musculares clônicas isoladas ou bilaterais e simétricas; quando mais intensa ainda, pode evoluir para uma convulsão tipo grande mal. Aliás, não é rara a associação, principalmente em sucessão cronológica, dessas duas formas clínicas de crise epiléptica.

A crise do grande mal (G.M.) pode, também, ser manifestação inicial de uma crise epiléptica, havendo, nesse caso, de inicio a descarga cerebral por ondas rítmicas, síncronas, de 4 a $3 \mathrm{c} / \mathrm{s}$ e de elevado potencial, seguida ou não de descargas rápidas de ondas também de elevado potencial. Sua eclosão significa que os sistemas diencefálicos foram os primàriamente ativados. Não há, como vimos, diferença clínica ou eletrencefalográfica entre a crise G.M. como fenômeno inicial e aquela subseqüente a uma crise bravais-jacksoniana ou a uma crise tipo pequeno mal. A rise do grande mal epiléptico é o lugar comum para onde convergem tôdas as manifestações paroxísticas de epilepsia, desde que suficientemente intensas para ativar os sistemas diencefálicos que controlam a função cerebral como um todo. A epilepsia tipo grande mal não é uma forma especial de epilepsia e sim uma manifestação final de qualquer crise epiléptica.

A experimentação em gatos ${ }^{i}, 12$ demonstron que, estimulando determinados núcleos da região intralaminar do tálamo, é possível reproduzir as crises clínicas do P.M. e as disritmias que as caracterizam - sucessão al. ternada das ondas $3 \mathrm{c} / \mathrm{s}$ de elevado potencial e das espículas (complexo ondas e espículas). A intensificação do estímulo experimental pode levar o animal à torção tônica do corpo e à crise convulsiva epiléptica. Ainda mais, não só o estímulo direto sôbre tais núcleos intratalâmicos, mas também o estímulo indireto por meio de excitação cortical, criando artificialmente focos epileptógenos, podem determinar a eclosão das disritmias bilaterais síncronas por ondas e espículas, assim como desencadeiam manifes- 
taçōes clínicas idênticas à da crise tipo pequeno mal; isto é mais fàcilmente obtido quando a excitação cortical é dirigida sôbre certas áreas frontais e temporais.

Propositadamente ficou até agora fora desta dissertação o problema da crise epiléptica psicomotora (Psm.). A razão é que êste capítulo é dos mais discutidos e constitui o ponto principal das controvérsias que a Escola Neurológica de Montreal mantém com outras, particularmente com a de Gibbs, em Chicago.

Certas áreas temporais profundas e frontais (face mesial e face orbitária do lobo frontal) quando excitadas ou quando sede de foco epileptógeno ativo, produzem manifestações clínicas diferentes daquelas obtidas com a excitação das demais áreas cerebrais da convexidade; tais manifestações são complexas, envolvendo funções que fazem parte da própria personalidade. A crise epiléptica focal dessa região se manifesta separando instantâneamente o paciente de seu corpo e de suas experiências passadas; o paciente conserva sua coordenação sensitivo-motora, é capaz de agir, de executar alguns atos mais automatizados de sua vida diária, de reagir quando se tenta detê-lo, mas tudo isto esquemàticamente, por vêzes brutalmente, incapaz que é de um ato que modifique sua ação em face do ambiente externo. 0 paciente é, nesse momento, um autômato, inconsciente do que está fazendo, não guardando memória alguma do que se passa durante a crise. São estas manifestações clínicas de automatismo que caracterizam a chamada crise psicomotora. Elas podem sobrevir isoladas nos ataques de epilepsia dêsse tipo, como podem ser manifestações mais ou menos duradouras no período pós-crise de un ataque de tipo grande mal, por exemplo. A explicação fisiopatológica dêsse automatismo é que a descarga epilêptica, atingindo os sistemas diencefálicos centrais, inativa-os momentâneamente e, com isso, acarreta o estado de inconsciência mais ou menos completa por repercussão imediata sôbre tôda a corticalidade ${ }^{6,10}$.

A experimentação já havia mostrado que os estímulas nessas áreas são muito mais fácil e ràpidamente conduzidos para os sistemas diencefálicos centrais; a anatomia explica o fato perfeitamente pela cxistência de muito mais íntimas conexões entre essas áreas e tais sistemas do que entre êstes e as demais áreas da corticalidade cerebral; estas conexões utilizam, como principal via, o fórnice. A experiência da Escola de Montreal mostra que a grande maioria dos epilépticos com crises psicomotoras, isoladas ou associadas a crises G.M., evidenciam um foco temporal profundo ou frontal orbitário, seja ao exame eletrencefalográfico ou na mesa operatória sob o contrôle do eletrocorticograma.

A característica eletrencefalográfica da epilepsia psicomotora (disritmias por $6 \mathrm{c} / \mathrm{s}$ ), admitida clàssicamente desde os trabalhos de Gibbs e Lennox, se explica porque os sistemas tálamo-corticais dessa região se exteriorizam mais por disritmias por $6 \mathrm{c} / \mathrm{s}$, enquanto que outros o fazem por disritmias outras, em particular a $3 \mathrm{c} / \mathrm{s}$, como já vimos. Durante o ato cirúrgico, em face de um foco temporal profundo, não raro a sucessão de espículas no eletrocorticograma conseqüente à ativação por estímulo elétrico 
do foco, se organiza ràpidamente em disritmias por $6 \mathrm{c} / \mathrm{s}$, assim que a crise clínica se processa.

Também as clássicas ondas por tôpo serrilhado que Gibbs havia descrito na epilepsia psicomotora são hoje reconhecidas, pela Escola de Montreal e pelo próprio Gibbs ${ }^{21}$, como espículas positivas, bem evidentes no exame eletrencefalográfico com métodos unipolares, tomando as orelhas como base. Elas, igualmente, identificam foco epileptógeno ativo em áreas temporais anteriores.

A epilepsia psicomotora não é, pois, para Jasper e colaboradores, uma forma especial de epilepsia, e sim uma manifestação focal de determinadas áreas cerebrais, tal como a epilepsia bravais-jacksoniana o é das áreas sômato-sensitivas. As características funcionais das áreas afetadas é que dão o quadro clínico dêste tipo de crise epiléptica.

Vemos, pois, que as manifestações clínicas e eletrencefalográficas das diversas formas de crise convulsiva epiléptica, assim cono as excitações experimentais de núcleos intratalâmicos, são perfeitamente concordantes em seus resultados finais. Há, sem dúvida, singular coinciuência dos resultados de estudos sóbre o sistema reticular tálamo-hipotalâmico e sôbre os relacionados com a epilepsia. A crise epiléptica é devida à ativação dêsse sistema central controlador da função cortical como um todo, o único capaz de recrutar tôdas as áreas corticais e fazê-las reagir de modo síncrono e global. Este sistema constitui "o mais alto nível" na integração do sistema nervoso, no sentido de H. Jackson, como demonstra Penfield ${ }^{6}$, se bem que, anatômicamente, esteja situado em posição inferior. Sua descarga, determinando um açambarcamento funcional momentâneo de todo córtex e inibindo-o, determina a perda súbita de consciência, o que Penfield identifica com a crise do pequeno mal epiléptico (highest level seizure); se a descarga fôr mais intensa, a perda de consciência inicial pode ser seguida de queda do paciente (perda do contrôle do tono postural, que sugere inativação de mecanismos mesencefálicos), ou em grau maior, de convulsão generalizada (crise clínica do grande mal epiléptico). A fisiopatologia de ambas manifestações epilépticas é, pois, uma só.

A descarga dêste sistema pode ser secundária a fatôres cerebrais (focos epileptógenos, tais como os das epilepsias bravais-jacksonianas, que em sua descarga ativam o sistema central), extracerebrais -- tóxicos (álcool), infecciosos (estados febris) ou metabólicos (hipoglicemia) - ou a fatôres próprios que fazem com que êste sistema seja anırmalmente lábil e mais fàcilmente reaja, provocando a sincronização das diversas áreas cerebrais, determinando a crise epiléptica.

Nos primeiros grupos situam-se os casos de epilepsia sintomática, no último os de epilepsia idiopática. Esta seria devida a distúrbios congênitos, herdados, verdadeira disgenesia de um sistema que lhe conferiria essa anormal labilidade para reagir convulsivamente. Está perfeitamente assente, desde os trabalhos de Lennox e col. ${ }^{22}$, que esta característica que torna o paciente um epiléptico latente é hereditàriamente transmissível e, eletren- 
cefalogràficamente, evidenciável pelo aparecimento de disritmias cerebrais bilaterais e difusas, obedecendo às leis de Mendel como fator recessivo.

A disgenesia do sistema reticular tálamo-hipotalâmico explica a tendência a crises epilépticas. Naturalmente haverá, no sistema nervoso dêsses pacientes, outras disgenesias que sirvam de base para tôdas as outras manifestaçôes de temperamento e de intelecto tão bem conhecidas na personalidade do epiléptico. Estamos, neste terreno, em pleno período de evolução de conhecimentos. Gibbs ${ }^{21}$ já fala na possibilidade de que "a tendência ao foco em área temporal anterior possa ser herdada", para explicar a frequência com que há epilepsia em familiares de epilépticos com crises do tipo psicomotor.

Aliás, entre nós, no Hospital de Juqueri, Peres Velasco ${ }^{23}$ tem encontrado assimetria de desenvolvimento dos hemisférios cerebrais, particularmente evidentes nos sistemas do rinencéfalo, fórnice, núcleo amigdalino e núcleos ventrais do tálamo e hipotálamo, na maioria dos pacientes de epilepsia que foram à necropsia. Este achado anatômico condiz perfeitamente com a concepção dinâmica da epilepsia que vimos enunciando, pois êsses núcleos são os mais ìntimamente relacionados com o sistema reticular tá. lamo-hipotalâmico.

\section{DIAGNOSTICO TOPOGRAFICO E ETIOLOGICO}

$\mathrm{Na}$ prática clínica diária, como primeiro passo ao examinar um doente portador de convulsões, cumpre fazer o diagnóstico diferencial entre epilep. sia sintomática e epilepsia idiopática.

No Montreal Neurological Institute o doente suspeito de epilepsia é submetido a uma rotina extensa de exarres que, iniciada com meticulosa anamnese, passa pelo exame neurológico e psiquiátrico, pelos exames eletrencefalográfico e radiológico do crânio e, não raro, vai ao pneumencefalograma.

Com os elementos fornecidos por êsses exames, particularmente pelo eletrencefalográfico, pode-se, desde logo, fazer o diagnóstico diferencial entre epilepsia idiopática e epilepsia sintomática (que lá preferem denominar "convulsões cerebrais", sòmente) em 90 a $95 \%$ dos casos. Sòmente o diagnóstico de epilepsia sintomática em um paciente, livrando-o e aos seus fa. miliares do estigma da palavra "epilepsia - mal hereditário", já é compensação suficiente para tôda essa investigação semiológica.

Por meio da anamnese meticulosa procura-se precisar o tipo ou os tipos de crises apresentadas pelo paciente, levando em conta que crises tipo P.M. e crises tipo G.M. são as que se apresentam nos epilépticos idiopáticos, enquanto que todos os demais tipos de crises são focais, portanto, dependentes de um fator lesional ou irritativo cerebral, e podem evoluir, também, para crises tipo grande mal. O quadro abaixo dá uma icéeia sumária dêsses tipos de epilepsia: 


\begin{tabular}{|c|c|}
\hline Localização do foco & Sintomas iniciais da crise \\
\hline Giro pós-central $\ldots \ldots \ldots \ldots$ & Fenômenos sômato-sensitivos. \\
\hline I.obo occipital $\ldots \ldots$ & Fenômenos visuais. \\
\hline Primeira circunvolução temporal. & Fenômenos auditivos ou vertiginosos. \\
\hline Face interna do lobo temporal .. & Fenômenos olfativos. \\
\hline Vizinhança da ínsula de Reil .... & Fenômenos epigástricos e gástricos. \\
\hline Circunvolução pré-central ... & $\begin{array}{l}\text { Fenômenos sômato-motores (epilepsia jack- } \\
\text { soniana). }\end{array}$ \\
\hline $\begin{array}{c}\text { Anterior à circunvolução pré-cen- } \\
\text { tral } \quad \ldots \ldots \ldots \ldots \ldots \ldots \ldots \ldots \ldots \ldots \ldots\end{array}$ & $\begin{array}{l}\text { Fenômenos de torção da cabeça e olhos pa- } \\
\text { ra o lado oposto, conservando-se a con- } \\
\text { sciência do paciente (crise controversiva } \\
\text { consciente). }\end{array}$ \\
\hline Area pré-frontal. & Crise controversiva inconsciente. \\
\hline Zona de Broca ....... & Fenômenos de afasia. \\
\hline $\begin{array}{l}\text { Borda superior da cissura de Syl- } \\
\text { vius, c. rolândica } \ldots \ldots \ldots \ldots \ldots\end{array}$ & Fenômenos de mastigação e deglutição. \\
\hline Córtex temporal, médio e anterior & $\begin{array}{l}\text { Fenômenos complexos de ilusão (micropsia, } \\
\text { macropsia, sensação de familiaridade ou } \\
\text { de estranheza ao ambiente - fenômeno do } \\
\text { já visto) ou de verdadeira alucinação, } \\
\text { geralmente do tipo onírico. }\end{array}$ \\
\hline
\end{tabular}

Os fenômenos que iniciam as crises provocadas por lesões focais no córtex temporal - parte média e anterior - constituem as chamadas auras ou crises psíquicas. Entre estas e os fenômenos de automatismo e a assim chamada crise de tipo psicomotor, há apenas um passo, por mecanismos de condução da descarga do foco aos centros diencefálicos e comprometimento mais ou menos acentuado da consciência.

A evidenciação clínica de um dos tipos de crise assinalados no quadro acima, particularmente se acompanhada de síndrome neurológica ou psiquiátrica correspondente à área topográfica suspeita (distúrbios permanentes ou transitórios da motricidade, da sensibilidade, da visão, etc., fora das crises epilépticas), permite o diagnóstico clínico de lesão focal, com topografia correspondente à da função afetada.

Ao exame eletrencefalográfico (EEG) caberá, então, comprovar o diagnóstico topográfico. Este exame é feito segundo uma rotina técnica bastante extensa e repetida, se necessário, e sempre ativado com a hiperventilação pulmonar durante 2 minutos. Quando permanece ainda dúvida sôbre o tipo de alteração ou principalmente sua exata localizaçáo, é feita injeção intravenosa de metrazol ${ }^{9}$ com diluição e técnica adequadas.

Os detalhes gráficos obtidos pelo EEG e que permitem o diagnóstico de epilepsia idiopática ou de crises convulsivas por lesão cerebral fócal são a tradução daqueles fenômenos elétricos que descrevemos acima a respeito 
da fisiopatologia da crise convulsiva. As descargas focais ou as disritmias bilaterais síncronas estão presentes, na grande maioria dos pacientes, nos intervalos das crises, embora sua intensidade não seja suficiente para determinar essas crises (descargas subclínicas). $\mathrm{O}$ diagnóstico e a localização podem ser feitos com um ou mais exames eletrencefalográficos em 90 a 95\% dos $\operatorname{casos}{ }^{15}$.

Os dados abaixo, tirados de Jasper ${ }^{15}$, constituem uma súmula dos elementos eletrencefalográficos considerados mais característicos em cada grupo de epilépticos:

1) Epilepsia focal cortical: a) Foco cortical superficial na convexidade - EEG mostrando espículas isoladas, localizadas e unilaterais. Atividade relativamente normal nas demais áreas. b) Foco cortical oculto -EEG com ondas "sharp" esporádicas, paroxismos de ritmo 2 a $6 \mathrm{c} / \mathrm{s}$, mais difusas, unilaterais ou bilaterais em áreas homólogas de ambos hemisférios cerebrais.

2) Epilepsia por múltiplos focos (lesões difusas coriicais) : EEG com ondas "sharp" ou ondas lentas, esporádicas. Ocasionalmente, seqüências rítmicas. Considerável independência da atividade de ambos hemisférios. Pequena ou nenhuma atividade normal de base.

3) Epilepsia focal subcortical: EEG mostrando várias formas de distúrbios de projeção, por vêzes ondas lentas e ondas "sharp", em geral aparecendo síncronas e bilaterais em áreas homólogas de ambos hemisférios. Atividade de hase muitas vêzes perturbada periòdicamente.

4) Epilepsia idiopática: a) Pequeno mal - EEC com ondas e espículas bilaterais, síncronas, com freqüência $3 \mathrm{c} / \mathrm{s}$; tráçado relativamente normal entre os ataques. b) Grande mal - EFG mostrando, muitas vêzes, quadro idêntico ao do pequeno mal, mas com espículas mais proemninentes. Por vêzes, aparecimento difuso de ritmos rápidos e espiculas múltiplas, por paroxismos. c) Epilepsia mioclônica - EEG com descargas de ondas lentas e múltiplas espículas, predominantemente sôbre os lobos frontais, em curtos paroxismos.

Feito o diagnóstico de crise convulsiva, de origem cerebral, e, principalmente, de origem por lesão focal cerebral, a etapa seguinte é o diagnóstico do fator causal.

$\mathrm{Na}$ anamnese, antes de tudo, procura-se elucidar a existência de herança similar, de perturbações na gravidez, de perturbações no parto (de particular importância são os traumatismos de parto), das moléstias de primeira infância (convulsões durante as moléstias da primeira infância, particularmente a coqueluche) e de traumatismos crânio-encefálicos.

E' surpreendente, no Montreal Neurological Institute, a freqüência de crises convulsivas relacionadas com lesões cerebrais adquiridas precocemente, nos traumas de parto ou nas lesões na primeira infância (traumatisınos, infecções), cujo diagnóstico clínico e eletrencefalográfico tem comprovação nos exames radiológico, pneumencefalográfico ou na mesa de cirurgia. Nes- 
ta, são particularmente freqüentes as lesões de circunvoluções temporais (microgiria, bordo de foco de amolecimento, em geral lesões cujo exame histo. patológico mostra serem secundárias, adquiridas). 0 exame radiológico do crânio, feito de modo acurado e por radiologistas experimentados, mostra, com grande freqüência, nesses casos, assimetria de desenvolvimento, particularmente das fossas temporais. $\mathrm{O}$ exame pneumencefalográfico confirma, na grande maioria dos casos, os achados da radiologia simples, mostrando, seja alargamento dos sulcos intergirais, seja dilatação, global ou em setores, dos cornos dos ventrículos laterais, particularmente nas lesóes temporais.

Além das causas etiológicas acima apontadas, os exames subsidiários podem mostrar a existência de tumores cerebrais, abscessos cerebrais, ineningoencefalites focais ou difusas, seqüelas de processos agudos pregressos e, bem mais raramente, cisticercose cerebral (a raridade desta última causa, no material do Montreal Neurological Institute, chamou nossa atenção, pois contrasta com a freqüência dela em nosso meio).

Após os exames clínico, eletrencefalográfico, radiológico e os exames de laboratório, são os pacientes, naquele Instituto, catalogados da seguinte forma: I. Convulsões cerebrais: a) causa. II. Convilsões cerebrais focais: a) localização; b) tipo; c) causa. IIJ. Epilepsia idiopática: a) pequeno mal; b) grande mal; c) mioclónica.

Para exemplificar:

Diagnóstico: Convulsão cerebral focal. Foco pré-central à direita. Típo: sômato-sensitivo. Causa: lesão traumática.

Diagnóstico: Convulsão cerebral focal. Foco temporal direito. Tipo: aura psíquira, automatismo. Causa: tumor cerebral.

Diagnóstico: Convulsão cerebral focal. Foco pré-frontal esquerdo. T'ipo: crise controversiva inconsciente. Causa: desconhecida.

O diagnóstico completo pode ser feito na maioria dos casos. Quando isto não seja possível, o tipo de crises ou o tipo de desordem eletrencefalográfica já dão orientação quanto à terapêutica sintomática, como veremos.

Falamos, até agora, sempre sôbre crises de tipo bern catalogável: convulsão por lesão cerebral focal bem definida ou epilepsia idiopática, igual. mente bem definida. Entre êsses dois extremos há grande número de pacientes cujas crises não são catalogáveis nem em um nem em outro dos grupos enunciados; referimo-nos aos que apresentaram uma ou duas convulsōes em tôda a sua vida, ou aos que apresentam sintomas paroxísticos frustos, tais como pequenos lapsos de consciência, crises "vagotônicas", crises vertiginosas, crises de mal-estar abdominal súbito, e todos aquêles que, desde Gowers, são catalogados como "marginais da epilepsia" (borderland of epilepsy). Estudos eletrencefalográficos feitos em Montreal ${ }^{17}$ eviden. ciam, em grande percentagem dêstes pacientes, a existência de disritmias frustas, bilaterais e difusas, confirmando o intimo parentesco dêstes casos com a epilepsia idiopática. 0 tipo das disritmias encontradas fêz com que tais crises sejam correlacionadas a distúrbios diencefálicos.

Colaterais a êles estão muitos casos das assim chamadas "convulsões infantis", particularmente aquelas sobrevindas durante estados febris. Es- 
tudos feitos no Montreal Neurological Institute ${ }^{15}$ mostraram que grande número das crianças que apresentaram tais convulsões apresenta EEG normal, e isso indica prognóstico benigno em relação à possibilidade de instalação ulterior de "epilepsia". Quando, porém, há tendência à repetição dessas "convulsões" durante as várias moléstias infantis, em muitos casos já o EEG mostra elementos positivos em favor de epilepsia e a medicação anticonvulsiva deve ser usada preventivamente. Estes elementos positivos, em grande maioria dos casos, são sinais de lesão cerebral focal sem outra sintomatologia clínica além de sua atividade epileptógena. Nestes casos, os traumatismos e processos infecciosos (particularmente ologênicos) que determinaram comprometimento meningocortical até então não diagnosticado são os mais freqüentes fatôres etiológicos.

\section{ORIENTAÇAO TERAPEUTICA}

A terapêutica deve ser orientada no sentido etiológico em primeiro lugar e, secundàriamente, no combate às crises, procurando medicamentos que elevem o limiar da excitabilidade focal e, ao mesmo tempo, dificultem a condução da energia de descarga focal aos centros vizinhos e aos profundos.

A experiência mostra que o tipo destas descargas, tal como são registradas no EEG, orienta na escolha do tipo de medicamento a ser usado. As descargas corticais do neopallium são melhor combatidas com os hidantoinatos, as corticais por condução (crises G.M. isoladas) o são com associação de barbitúricos e hidantoinatos, as do archipallium com a "Phenurone" e as do diencéfalo com a "Tridione" (crises de tipo (P.M.).

Ao lado disso, a terapêutica deve visar o doente epiléptico como um todo, procurando afastar os cofatôres somáticos (infecciosos, tóxicos, distúrbios da nutrição e endócrinos) e psíquicos (emocionais) capazes de desencadear as crises. 0 problema psicológico deve ser cuidadosamente encarado, procurando-se proporcionar aos pacientes, por intermédio de serviços psiquiátricos e sociais bem organizados, um ambiente familiar e de trabalho compreensivo às suas condições, assim como procurando afastar dêle o complexo de doença e reorientando-o social e profissionalmente.

\section{NEUROCIRURGIA DA EPILEPSIA}

Além dos casos de pacientes convulsivos em que a semiologia vem demonstrar a existência de tumor intracraniano ou de um abscesso cerebral, a terapêutica cirúrgica é reservada sòmente para os casos de epilepsia secundária a lesão focal cerebral, que se mostraram resistentes a um tratamento clínico bem orientado e bem seguido pelo paciente no mínimo durante 2 anos.

Os casos com foco cortical acessível ao neurocirurgião, clínica e eletrencefalogràficamente bem diagnosticados, quando resistentes à terapêutica medicamentosa, são encaminhados à mesa de neurocirurgia, onde, após craniotomia extensa, são submetidos a estudo eletrocorticográfico detalhado. E' pesquisado, assim, o foco epileptógeno com os eletrodos colocados diretamente sôbre o córtex. 0 foco pode dar sinais de evidência, espontâneamente, ou 
então é ativado pela hiperpnéia, ou, quando necessário, pela excitação elétrica direta do córtex. Estas despertam, não só a atividade elétrica do foco, tornando-o bem evidente ao eletrocorticograma (ECG), como reproduzem, não raro, a aura clínica apresentada usualmente pelos pacientes. A coincidência dêstes dados com os do exame pré-operatório do paciente é do mais alto valor.

$O$ foco cortical - em geral, lesão cicatricial meningocortical ou circunvolução atrófica por lesão em período precoce de seu desenvolvimento -é, então, cuidadosamente extirpado, com técnica especial ${ }^{8}$, para evitar a formação de nova cicatriz epileptógena, até que o exame eletrocorticográfico ulterior evidencie a inexistência de qualquer ponto elètricamente ativo. Os resultados obtidos por Penfield e colaboradores com essa cirurgia mostram $56 \%$ de curas num total de 76 pacientes com focos inteiramente removidos, observados de 1 a 7 anos após a intervenção. Note-se a significação dêstes resultados quando se lembra que foram obtidos em material clínico completamente resistente a tôda terapêutica clínica usual. A análise dêsses resultados mostra $76 \%$ de curas nos casos de focos por traumas de parto, $56 \%$ nos de cicatrizes meningoencefálicas (processos infecciosos) e $51 \%$ nos de trauma crânio-encefálicos. Operações no lobo frontal foram as de maior sucesso $(73 \%)$, vindo, a seguir, as praticadas em áreas sensitivo-motoras do córtex $(67 \%)$.

Este modo de encarar o problema da epilepsia no Montreal Neurological Institute é o resultado de 20 anos de trabalho contínuo orientado numa diretriz firme e apoiado na concepção teórica inigualável de Hughlings Jackson. Os resultados da observação clínica no doente epiléptico foram comprovados pelos da excitação direta da corticalidade cerebral durante $o$ ato neurocirúrgico, e ambos tiveram integral confirmação nos dados fornecidos ulteriormente pela eletrencefalografia e pela eletrocorticografia. $O$ avanço das concepções de Penfield e colaboradores sôbre a fisiopatologia das crises epilépticas foi imediatamente apoiado pelos novos conhecimentos da neurofisiologia cerebral e pelos resultados da provocação da crise epiléptica experimental - clínica e eletrencefalográfica - em animais, seja do tipo bravrais-jacksoniano, seja do pequeno ou do grande mal.

Tudo isso pode constituir uma hipótese; pode ter seus erros e suas falhas, mas convenhamos que constitui uma esplêndida hipótese de trabalho que permite enfrentar o árduo problema da epilepsia. Apliquêmo-lo em nosso meio, procuremos ver até que ponto, na prática, os casos podem ser enquadrados dentro dêstes esquemas e aguardemos quais os resultados úteis em benefício dessa legião de doentes estigmatizados com o. diagnóstico de epilepsia.

\section{BIBLIOGRAFIA}

1. Jasper, H. e Nichols, E. - Electrical signs of cortical function in epilepsy and allied disorders. Am. J. Psychiat., 94:835-850, 1938.

2. Jasper, H., Kershman, J. e Elvidje, A. - Electroencephalographic studies in injury of the head. Arch. Neurol. a. Psychiat., 44:328-350, 1940. 
3. Jasper, H. e Kershman, J. - Electroencephalographic classification of the epilepsies. Arch. Neurol. a. Psychiat., 45:903-943, 1941.

4. Penfield, W. e Erickson, Th. - Epilepsy and cerebral localization. Ch. C. Thomas Ed., Baltimore, 1941.

5. Jasper, H. e Penfield, W. - Electroencephalograms in post-traumatic epilepsy. Preoperative and postoperative studies. Am. J. Psychiat., 100:365, 1943.

6. Penfield, W. e Jasper, H. - Highest level seizures. Proc. A. Res. Nerv. a. Ment. Dis., 26:252-271, 1946.

7. Jasper, H. e Droogleever Fortuyn, J. - Experimental studies on the functional anatomy of petit mal epilepsy. Proc. A. Res. Nerv. a. Ment. Dis., 26:273-298, 1946.

8. Penfield, W. e Steelman, H. - The treatment of focal epilepsy by cortical excision. Ann. Surg., 126:741-762, 1947.

9. Cure, Ch., Rasmussen, Th. e Jasper, H. - Activation of seizures and electroencephalographic disturbances in epileptic and in control subjects with "metrazol". A rch. Neurol. a. Psychiat., 59:691-717, 1948.

10. Penfield, W. - Epileptic manifestations of cortical and supracortical discharge. EEG. a. Clin. Neurophysiol. J., 1:3-10, 1949.

11. Jasper, H. - Electrical signs of epileptic discharge. EEG. a. Clin. Neurophysiol. J., 1:11-18, 1949.

12. Hunter, J. e Jasper, H. - Effects of thalamic stimulation in unanaesthetized animals. EEG. a. Clin. Neurophysiol. J., 1:305-324, 1949.

13. Jasper, H. - Diffuse projection systems: the integrative action of the thalamic reticular system. EEG. a. Clin. Neurophysiol. J., 1:405-420, 1949.

14. Roy S. Swank - Synchronization of spontaneous electrical activity of cerebrum by barbyturate narcosis. J. Neurophysiol., 12:161-172, 1949.

15. Jasper, H. - a) Electroencephalography in child Neurology and Psychiatry. Pediatrics, 783-800 (junho) 1949. b) The electroencephalography in neurosurgery. Comptes rendus IV Congresso Neurológico Internacional, Paris, vol. 1, Masson Cie. Ed., Paris, pág. 21-26.

16. Penfield, W. - Classification of the epilepsies. Arch. Neurol. a. Psychiat., 60:107-118, 1948.

17. Kershman, J. - a) The borderland of epilepsy. A reconsideration. Arch. Neurol., a. Psychiat., 62:551-9, 1949. b) Syncope and seizures. J. Neurol., Neurosurg. a. Psychiat., 12:25-33, 1949.

18. Dempsey, E. W. e Morrison, R. S. - a) The production of rythmically recurrent cortical potentials after localized thalamic stimulation. Am. J. Physiol., 135:292:300, 1942. b) The electrical activity of a thalamocortical relay system. Am. J. Physiol., 138:282-296, 1943. c) A study of thalamocortical relations. Am. J. Physiol., $195: 281-292,1942$.

19. Magoun, H. W. e Rhines, R. - a) An inhibitory mechanism in the bulbar reticular formation. J. Neurophysiol., 9:165-172, 1946. b) Brain-stem facilitation of cortical motor response. J. Neurophysiol., 9:219-230, 1946.

20. Rose, J. E. e Woosley, C. - Organization of the mammalian thalamus and its relationships to the cerebral cortex. EEG. a. Clin. Neurophysiol. J., 1:391-404, 1949 .

21. Gibbs, F., Gibbs, E. e Fuster, B. - Psychomotor epilepsy. Arch. Neurol. a. Psychiat., 60:331-339, 1948.

22. Lennox, W. e Gibbs, F. - a) Inheritance of cerebral dysrhytmia and epilepsy. Arch. Neurol. a. Psychiat., 44:1155-1183, 1940. b) The brain wave pattern, an hereditary evidence from 74 "normal" pairs of twins. J. Heredity, 36:225-243, 1945.

23. Perez Velasco, O. - Achados anatômicos na epilepsia. Rev. Paulista de Med, 38:142, 1948. 